\title{
A Model for the Designing of Multimodal Transport Processes and the Concept of Its Integration with the EPLOS System
}

\author{
Mariusz Wasiak*, Paweł Leleń, Michał Kłodawski, Mariusz Izdebski, llona Jacyna-Gołda
}

\begin{abstract}
The paper proposes a new single criterion mathematical model for the designing of multimodal transport processes by taking into account the cargo's susceptibility and the concept of its inclusion into the EPLOS system, which is done as part of the EUREKA initiative. This system will integrate the data from logistics sources and transport and logistics infrastructure from many sources. In the first phase of its implementation, it will cover the Czech Republic, Poland, and the Baltic States. Using the EPLOS system integrating data from various sources needed to solve this problem is a proposal to overcome the main barrier to the effective planning of multimodal transport processes - a lack of reliable information.
\end{abstract}

Keywords: designing transport processes; EPLOS; European Portal of Logistics Services; multimodal transport

\section{INTRODUCTION}

The planning of technological processes in transport, especially when taking into account many of its branches, is a multi-faceted and complex process. It requires comprehensive knowledge of the features of individual transport technologies, as well as the physical configuration options of the supply chain and shipping offers. Thus, the correct implementation of this process is conditioned by the access to a lot of detailed information regarding transport offers, transport infrastructure, and transshipment terminals. An important part of this information is included in the EPLOS system, created as part of the EUREKA initiative. Hence, its use in the planning of multimodal transport processes can significantly simplify this process and, to some extent, automate it. The EPLOS system will integrate the data on logistics companies, as well as transport and logistics infrastructure, from many sources. In the first phase of its implementation, it will cover the Czech Republic, Poland, and the Baltic States.

The issue of modeling the selection of the multimodal transport technology concerning perishable products with particular regard to their transport susceptibility was, in formal terms, first described in scientific articles [1-5 $]^{1}$. However, in previous years, the issues related to the selection of multimodal transport technologies were considered in partial terms. Namely, some of the authors dealt exclusively with the key transport susceptibility of cargo in this area [714], while others, apart from this issue, proposed various approaches to optimizing the supply chain configuration [15$24]$, or they dealt exclusively with the issue of the selection of the means of transport for tasks $[25,26]$ or, e.g., optimization of transport routes [27-29].

It is noteworthy that in literature, the modeling of multimodal load-shifting technologies is recognized primarily from the perspective of planning routes for moving material goods and their transshipments between different

\footnotetext{
1 The simplification of this approach to the issue of the selection of unimodal transport technologies, including the choice of the means of
}

types of transport (see, e.g. [30] or [31]). In the model proposed in this article, by extending this issue considerably, the focus was also on the selection of freight transport forms and work resources. Additionally, which distinguishes the model presented below, it includes a formalized approach to the mapping of cargo transport susceptibility.

The model described, e.g., in [3], is quite complicated because it includes a significant number of features of perishable loads. The new model offers maximum simplification in this respect, which can be taken into account only in the case of loads sensitive to moisture, solar radiation, and temperature conditions. Some specific conditions necessary for perishable products are omitted here, as well as the issues regarding sensitivity to static and dynamic effects. However, only the costs were taken into account as the evaluation criterion. This model was further simplified by taking into consideration work resources instead of separately analyzing technical measures and employees. At the same time, in the presented model, the issue of the temporal availability of individual work resources was included, which means that it may have significant practical importance. Thus, the article proposes an original single criterion model for designing multimodal transport processes, taking into account the vulnerability of loads, selection of work resources, along with the temporal availability of work resources. Moreover, particular attention was paid to the scope of the required data for this model and references were made to the possibility of obtaining this data from the EPLOS system.

\section{A MODEL FOR DESIGNING MULTIMODAL TRANSPORT PROCESSES}

In accordance with the previous comments, the following subsections present a single criterion mathematical model for the selection of multimodal technologies for transporting perishable loads sensitive only to moisture, solar radiation,

transport and the form of transport loads has been described in the monograph [6]. 
and/or temperature conditions, taking into account the temporal availability of work resources. The adopted assumptions and elements of the model were characterized, as well as a formal record of decision variables, constraints, and the assessment criterion, which are transport baskets.

\subsection{Assumptions and General Form of the Model}

The basic assumption is the freedom to choose a transport technology for specific transport tasks, including the ability to choose the work resources with service under each technology. Transport technologies have been defined, taking into account transport forms, performed activities, displacement routes, and work resources with their service. On the other hand, the technological process within the technology was recorded as a series of ordered activities, of which for each is known: the form of the transport of loads, displacement routes and work resources with their service, which may be involved in its implementation.

Transport tasks included in the model relate to the movement of selected products, which may have a number of features determining their transport susceptibility. At the same time, only load features were seen as the most important due to their transport susceptibility and hence were taken into account. For each activity of the technological process, the possibility of choosing different forms of cargo transportation was assumed. The impact of the transport form of loads on their transport susceptibility was also taken into account.

It was also assumed that for each transport form, the number of load units that will fit in is known (equal to 1 in the case of loose cargo). Additionally, for each means of transport, the number of pieces of cargo that will fit in its cargo space when transported is known. This means that the issue of forming load units and planning the distribution of load units in the vehicle's cargo space - such as the problem of allocating employees to devices - has been excluded from this decision problem as a separate optimization issue.

Moreover, it was assumed that the used multimodal transport technologies must guarantee the safety of transported loads, taking into account their transport conditions. On the other hand, the assessment of the selection of multimodal transport technologies is carried out by taking into account the minimization of the costs of moving cargo.

Additionally, it was assumed that the problem of selecting a transport technology for tasks to be carried out within a specified time horizon was considered. As a consequence, individual technical resources, together with human resources, can be allocated in this period to perform only one activity identified in the technological process, and their time availability for individual activities is known due to their current load and location.

Considering the above, the model for selecting multimodal technologies for the transport of perishable products, $M D T$, was formally written as follows:

$$
M D T=\langle B F, P F, U F, T F, T M, Z M, O\rangle
$$

where:

$B F$ - loads,

$P F-$ form of transport,

$U F$ - work resources and their service,

$T F$ - displacement routes,

$T M$ - multimodal transport technologies,

$Z M$ - transport tasks,

$O$ - organization reflecting the manner of the implementation of transport tasks, including decisions regarding the selection of the transport technology and work resources with employees.

\subsection{Model Elements}

The loads $B F$ were mapped based on a set of their types $\boldsymbol{B}=\{1, \ldots, b, \ldots, B\}$ and a set of their characteristics $\boldsymbol{F}_{\boldsymbol{B}}$ :

$F_{B}=\left\{\left(m_{b}(b), t_{\min }(b), t_{\max }(b), \Delta t_{d o p}(b), w s(b), w w(b)\right): b \in B\right\}$

where:

$m_{b}(b)$ - the gross mass of one piece of load or unit package of $b^{\text {th }}$ type (for non-unit loads of any small value), $\mathrm{kg}$,

$t_{\min }(b)-$ the lowest permissible temperature for the transport of $b^{\text {th }}$ type load, $\mathrm{K}$,

$t_{\max }(b)$ - the highest permissible temperature for the transport of $b^{\text {th }}$ type load, $\mathrm{K}$,

$\Delta t_{\text {dop }}(b)$ - permissible temperature fluctuations during the transport of $b^{\text {th }}$ type load, $\mathrm{K}$,

$w s(b) \quad-$ the sensitivity of $b^{\text {th }}$ type load to solar radiation and light,

$\omega и(b)-$ the sensitivity of $b^{\text {th }}$ type load to water.

Similarly, the transport characters $P F$ were mapped, taking into account a set of numbers of their types $\boldsymbol{P}=\{1, \ldots, p, \ldots, P\}$ and a set of their characteristics $\boldsymbol{F}_{\boldsymbol{P}}$ :

$F_{P}=\left\{\left(o w(p), o s(p), w_{t}(p), t_{\min p}(p), t_{\max p}(p)\right.\right.$, $\left.\left.\Delta t_{\text {rzp }}(p), m_{p}(p),(N(p, b): b \in \boldsymbol{B})\right): p \in \boldsymbol{P}\right\}$

where:

$o$ ow $(p)$ - the ability to protect the load against water by the $p^{\text {th }}$ form of transport,

$o s(p)$ - the ability to protect the load against solar radiation and light by the $p^{\text {th }}$ form of transport.

$w_{t}(p)$ - the ability to change the temperature in the immediate vicinity of the load by the $p^{\text {th }}$ form of transport,

$t_{\min p}(p)-$ the min. air temperature in the immediate vicinity of the load for the $p^{\text {th }}$ form of transport, $\mathrm{K}$,

$t_{\max p}(p)-$ the max. air temperature in the immediate vicinity of the load for the $p^{\text {th }}$ form of transport, $\mathrm{K}$, 
$\Delta t_{r z p}(p)$ - the maximum temperature fluctuations in the immediate vicinity of the load for the $p^{\text {th }}$ form of transport, $\mathrm{K}$,

$m_{p}(p)-$ the tare for the load for the $p^{\text {th }}$ form of transport, $\mathrm{kg}$,

$N(p, b)$ - the capacity of the $p^{\text {th }}$ transport form defined in the number of load units of $b^{\text {th }}$ type, pcs.

Moreover, the work resources and their service $U F$ were mapped, taking into account a set of numbers of their types $U=\{1, \ldots, u, \ldots, U\}$ and a set of their characteristics $F_{U}$. However, in this case, the set $U$ was decomposed into a set of numbers of types:

- of means of transport with the service $U 1$,

- $\quad$ of loading devices with the service $U 2$.

Thus, a set of characteristics of the means of transport with the service $F_{U 1}$ and a set of characteristics of loading devices with the service $F_{U 2}$ was obtained:

$F_{U 1}=\left\{\left(N U(u), t_{\min r}(u), t_{\max r}(u), \Delta t_{r z}(u), V_{s r}(u), o W_{u}(u)\right.\right.$, $o S_{u}(u), k_{t s}(u), k_{t t}(u), k_{t w}(u), \boldsymbol{U U}(u), \boldsymbol{P}_{U 1}(u),\left(N_{p}(u, p, b)\right.$ : $\left.\left.\left.p \in \boldsymbol{P}_{U 1}(u), b \in B\right)\right): u \in \boldsymbol{U}, \boldsymbol{U U}(u) \subseteq \boldsymbol{U} 2, \boldsymbol{P}_{U 1}(u) \subseteq \boldsymbol{P}\right\}$

where:

$N U(u)-$ number of the $u^{\text {th }}$ type of the means of transport available with the service, pcs,

$t_{\min r}(u)$ - the minimum air temperature during transport in the cargo space of the means of transport of the $u^{\text {th }}$ type, $\mathrm{K}$,

$t_{\max r}(u)$ - the maximum air temperature during transport in the cargo space of the means of transport of the $u^{\text {th }}$ type, $\mathrm{K}$,

$\Delta t_{r z}(u)$ - the maximum air temperature fluctuations during transport in the cargo space of the means of transport of the $u^{\text {th }}$ type, $\mathrm{K}$,

$V_{s r}(u) \quad$ - the average speed of transport of the means of transport of the $u^{\text {th }}$ type, $\mathrm{km} / \mathrm{h}$,

$o W_{u}(u)$ - the possibility of protecting against the direct effects of water on the load by the means of transport of the $u^{\text {th }}$ type,

$o S_{u}(u)-$ the ability to provide load protection against light and solar radiation for the means of transport of the $u^{\text {th }}$ type,

$k_{t s}(u)$ - the unit cost of operation depending on the mileage for the means of transport of the $u^{\text {th }}$ type, $\mathrm{PLN} / \mathrm{km}$,

$k_{t t}(u)$ - the unit cost of operation depending on transport time for the means of transport of the $u^{\text {th }}$ type, $\mathrm{PLN} / \mathrm{h}$,

$k_{t w}(u)-$ unit labor cost dependent on the time of work of all service employees for the means of transport of the $u^{\text {th }}$ type, PLN/h,
$U U(u)$ - a set of numbers of the types of loading devices with the service that can be operated by the means of transport of the $u^{\text {th }}$ type,

$P_{U 1}(u)$ - a set of numbers of the load transport forms served by the means of transport of the $u^{\text {th }}$ type,

$N_{p}(u, p, b)$ - the capacity of the means of transport of the $u$ th type in the number of units of the $p^{\text {th }}$ transport form for the $b^{\text {th }}$ type of load, pcs.

$$
\begin{gathered}
\boldsymbol{F}_{U 2}=\left\{\left(F_{Q}(u), k_{j}(u), \boldsymbol{k}_{W}(u), \boldsymbol{P}_{U 2}(u),\left(W(u, p): p \in \boldsymbol{P}_{U 2}(u)\right)\right)\right. \\
\left.: u \in U 2, \boldsymbol{P}_{U 2}(u) \subseteq \boldsymbol{P}\right\}
\end{gathered}
$$

where:

$F_{Q}(u)$ - the load capacity of the $u^{\text {th }}$ type loading device, $\mathrm{kg}$,

$k_{j}(u) \quad-$ the hourly labor cost of the $u^{\text {th }}$ type loading device, PLN/h,

$k_{w}(u) \quad$ - the unit labor cost dependent on the time of work for all employees operating the $u^{\text {th }}$ type loading device, $\mathrm{PLN} / \mathrm{h}$,

$P_{U 2}(u)$ - the set of numbers for the form of cargo transportation supported by the $u^{\text {th }}$ type loading device,

$W(u, p)$ - the practical efficiency of the $u^{\text {th }}$ type loading device when handling load units in the $p^{\text {th }}$ transport form, pcs/h.

The movement routes $T F$ in the model were mapped, taking into account the set of their numbers $T=\{1, \ldots, t, \ldots, T\}$ and a set of their characteristics $\boldsymbol{F}_{\boldsymbol{T}}$ :

$$
\begin{aligned}
F_{T}= & \left\{m p(t), m k(t), s(t), T U(t),\left(t_{d o d}(t, u): u \in U\right),\right. \\
& \left(k_{d o d}(t, u): u \in U\right),\left(t_{\text {dod } 2}(t, u): u \in U\right), \\
& \left.\left(k_{\text {dod } 2}(t, u): u \in U\right): t \in T, T U(t) \subseteq U\right\}
\end{aligned}
$$

where:

$m p(t) \quad-$ the starting point of the $t^{\text {th }}$ route,

$m k(t) \quad-$ the end point of the $t^{\text {th }}$ route,

$s(t) \quad-$ length of the $t^{\text {th }}$ route, $\mathrm{km}$,

$T U(t) \quad-$ a set of numbers of the types of work resources together with the service authorized for traffic on the $t^{\text {th }}$ route,

$t_{d o d}(t, u) \quad-$ the expected time of breaks and stops of the $u^{\text {th }}$ type of work for the $t^{\text {th }}$ route, $\mathrm{h}$,

$k_{d o d}(t, u)$ - the costs of using the infrastructure for the $t^{\text {th }}$ route and the $u^{\text {th }}$ work resources, PLN,

$t_{d o d 2}(t, u)$ - the expected working time of the $t^{\text {th }}$ route for all employees operating the $u^{\text {th }}$ work resources, h,

$k_{\text {dod } 2}(t, u)$ - additional labor costs for all employees working with the $u^{\text {th }}$ type of work equipment during the $t^{\text {th }}$ route, PLN. 
The multimodal transport technologies $T M$ were mapped, taking into account a set of numbers of their types $D=\{1, \ldots, d, \ldots, D\}$ and a set of technological processes that make up these technologies $P T$. Additionally, each transport technological process distinguished within the $d^{\text {th }}$ type of technology was defined by taking into account the ordered set of activities that create it $I(d)=\{1, \ldots, e, \ldots, E(d)\}$ as follows:

$$
\begin{gathered}
P T(d)=\left\langle\left(p t_{e}(d), n t_{e}(d), t t_{e}(d), U T_{e}(d), \mathrm{TD}_{e}(d)\right): e \in I(d),\right. \\
\left.p t_{e}(d) \in P, n t_{e}(d) \in\{0,1\}, t t_{e}(d) \in T, U T_{e}(d) \subseteq U\right\rangle, d \in D
\end{gathered}
$$

where:

$p t_{e}(d)$ - the cargo transport form number for the $e^{\text {th }}$ activity of the $d^{\text {th }}$ technology,

$n t_{e}(d)$ - the type number of the $e^{\text {th }}$ operation of the $d^{\text {th }}$ technology, where for loading activities $n t_{e}(d)=0$, and for transport activities $n t_{e}(d)=1$.

$t t_{e}(d)$ - the movement route number for the $e^{\text {th }}$ activity of the $d^{\text {th }}$ technology,

$U T_{e}(d)$ - a set of numbers of the types of work resources together with the support of technology acceptable for the $\mathrm{e}^{\text {th }}$ activity of the $d^{\text {th }}$ technology,

$\operatorname{TD}_{e}(d)$ - the vector of moment vectors at which subsequent work resources of particular types may be made available, together with the support for the $e^{\text {th }}$ activity of the $d^{\text {th }}$ transport technology $\operatorname{TD}_{e}(d)=\left[\left[t d_{e}(d, u, n u(u)) \in \mathbb{R}^{+}: n u(u)\right.\right.$ $=1, \ldots, N U(u)], u \in U(z)]$, min.

Whereas the set of numbers of the transport task was defined as $Z=\{1, \ldots, Z, \ldots, Z\}$, while the $z^{\text {th }}$ transport task was defined as follows:

$$
Z T(z)=\left\langle\boldsymbol{B}(z), \mathrm{N}(z), m_{p}(z), m_{d}(z), t_{p}(z), t_{d}(z), P(z), U(z)\right),
$$

where:

$\boldsymbol{B}(z) \quad-$ a set of load type numbers for the $z^{\text {th }}$ transport task, $N(z)$ - the vector of the number of loads of individual types for $\quad$ the $\quad z^{\text {th }} \quad$ transport task,
$\mathbf{N}(z)=\left[n(z, b): n(z, b) \in \mathbb{R}^{+}, b \in B(z)\right]$, pcs,

$m_{p}(z)$ - the place where the loads are picked up for the $z^{\text {th }}$ transport task,

$m_{d}(z)-$ the place where the loads are picked up for the $z^{\text {th }}$ transport task,

$t_{p}(z)$ - earliest pickup time for the $z^{\text {th }}$ transport task,

$t_{d}(z)$ - the latest delivery of goods for the $z^{\text {th }}$ transport task,

$\boldsymbol{P}(z)$ - a set of numbers of the transport form types possible to use for the $z^{\text {th }}$ transport task,
$U(z)$ - a set of numbers of the types of work resources together with the service that can be used to carry out the $z^{\text {th }}$ transport task.

Considering the above, a set of numbers of types of multimodal transport technologies, which can be used to implement the $z^{\text {th }}$ transport task, was defined as follows:

$$
\begin{aligned}
& D(z)=\left\{d: \forall e \in I(d)\left(\left(p t_{e}(d) \in \boldsymbol{P}(z)\right) \wedge\left(t t_{e=1}(d)\right)=m_{p}(z)\right)\right. \\
& \left.\left.\wedge\left(t t_{e=E(d)}(d)\right)=m_{d}(Z)\right) \wedge\left(U T_{e}(d) \cap U(z) \neq \varnothing\right)\right\}, z \in Z
\end{aligned}
$$

\subsection{Decision Variables}

The model includes the following four types of decision variables:

- a binary decision variable $x(z, d) \in\{0,1\}$ that assumes a value of 1 when the $z^{\text {th }}$ transport task is to be performed according to the $d$-type technology and 0 in the opposite case,

- $\quad$ an integer decision variable $y(z, d, e, u) \in \mathcal{N} \cup\{0\}$ for the interpretation of the number of $u^{\text {th }}$ work resources together with the service that should be used to perform the $e^{\text {th }}$ action distinguished in the $d^{\text {th }}$ technology during the implementation of the $z^{\text {th }}$ transport task,

- a binary decision variable $z(z, d, e, u, n u(u)) \in\{0,1\}$ that assumes a value of 1 when the $n u(u)^{\text {th }}$ mode of transport of the $u^{\text {th }}$ type along with the service should be used to perform the $e^{\text {th }}$ action distinguished in the $d^{\text {th }}$ technology during the implementation of the $z^{\text {th }}$ transport task and 0 otherwise,

- the decision variable $\tau(z, d, e)$ with the interpretation of the moment of commencement of the $e$-action in connection with the implementation of the $z^{\text {th }}$ transport task according to the $d$-type technology.

In accordance with the above, the next of the considered decision variables relate to the selection of a transport technology for tasks, the selection of work resources with service for the implementation of individual activities under the given technologies, and the moment of commencing the implementation of subsequent activities.

\subsection{Constraints}

The constraints included in the model result from the characteristics considered to be significant, i.e. load characteristics, characteristics of loading forms, and means of transport, as well as from the characteristics of multimodal transport technologies themselves. It was assumed that the implementation of tasks should be ensured by selecting technologies for them (1), while for the activities included in the selected technologies, it is necessary to choose work resources with service (2) and (3). It is also necessary to take into account the constraints resulting from the available number of these work resources (4). Additionally, the requirements regarding the transport temperature (5)-(7), as well as the protection of the load against the adverse effects 
of water (8) and solar radiation and light (9), were taken into account. The following constraint includes the possibility of cooperation of the means of transport with the loading devices (10) and (11), as well as the possibility of handling the selected forms of transport by the chosen means of transport (12) and (13), the possibility of using them to perform specific tasks (14), the selection for individual technological activities (15) and their movement on individual routes (16), or admissibility of a selection of individual technologies for the considered transport tasks (17). The conditions resulting from the permissible loading of loading devices (18) are also important. The last of the constraints result from the temporary availability of work resources for the implementation of tasks and the earliest start and end moments of completion of individual tasks (19)-(22), and from the unambiguous allocation of subsequent work resources of individual types (23).

$$
\forall z \in \boldsymbol{Z} \quad \sum_{d \in \boldsymbol{D}(z)} x(z, d)=1
$$

$\forall z \in \boldsymbol{Z} \quad \forall d \in \boldsymbol{D}(z) \quad \forall e \in \boldsymbol{I}(d): n t_{e}(d)=0$

$\sum_{u \in \boldsymbol{U} \boldsymbol{T}_{\boldsymbol{e}}(d) \cap \boldsymbol{U}(z) \cap \boldsymbol{U} 2: p t_{e}(d) \in \boldsymbol{P}_{\boldsymbol{U} 2}(u)} \sum y(z, d, e, u) \geq x(z, d)$

$\forall z \in Z \forall d \in D(z) \forall e \in I(d): n t_{e}(d)=1 \quad x(z, d) \leq$ $\sum_{\substack{u \in U T_{e}(d) \cap U(z) \cap U 1: \\ p t_{e}(d) \in P_{U 1}(u)}} y(z, d, e, u) \cdot \sum_{b \in B(z)} \frac{N_{p}\left(u, p t_{e}(d), b\right)}{n(z, b)}$

$\forall u \in U l \sum_{z \in Z} \sum_{d \in D(z)} \sum_{e \in I(d): u \in U T_{e}(d)} y(z, d, e, u) \leq N U(u)$

$\forall_{z \in Z} \forall \forall_{d \in D(z)} \forall_{e \in I(d): n t_{e}(d)=1} \forall_{u \in \boldsymbol{U} I}$

$t_{\min r}(u) \cdot\left[1-w_{t}\left(p t_{e}(d)\right)\right]+t_{\min p}\left(p t_{e}(d)\right) \cdot w_{t}\left(p t_{e}(d)\right)>$ $\operatorname{sgn}(y(z, d, e, u)) \cdot \max _{b \in B(z)}\left\{t_{\min }(b)\right\}$

$\forall \forall_{z \in Z} \forall d \in D(z) \forall \forall_{e \in I(d): n t_{e}(d)=1} \forall_{u \in U}$ $\operatorname{sgn}(y(z, d, e, u)) \cdot\left[t_{\max r}(u) \cdot\left[1-W_{t}\left(p t_{e}(d)\right)\right]+\right.$ $+t_{\max p}\left(p t_{e}(d)\right) \cdot w_{t}\left(p t_{e}(d)\right] \leq \min _{b \in B(z)}\left\{t_{\max }(b)\right\}$

$\forall_{z \in Z} \forall \forall_{d \in D(z)} \forall_{e \in I(d)} n t_{e}(d)=1 \forall_{u \in \boldsymbol{U}}$ $\operatorname{sgn}(y(z, d, e, u)) \cdot\left[\Delta t_{r z}(u) \cdot\left[1-w_{t}\left(p t_{e}(d)\right)\right]+\right.$ $+\Delta t_{\text {rzp }}\left(p t_{e}(d)\right) \cdot w_{t}\left(p t_{e}(d)\right] \leq \min _{b \in B(z)}\left\{\Delta t_{d o p}(b)\right\}$

$\forall \forall_{z \in Z} \forall d \in D(z) \forall_{e \in I(d): n t_{e}(d)=1} \forall u \in U$ $\max _{b \in B(z)}\{w W(b)\} \cdot \operatorname{sgn}(y(z, d, e, u))=$ $=\max \left\{o w\left(p t_{e}(d)\right) ; o w_{u}(u)\right\}$

$\forall \forall_{z \in Z} \forall d \in D(z) \forall \forall_{e \in I(d): n t_{e}(d)=1} \forall_{u \in U l}$ $\max _{b \in B(z)}\{w s(b)\} \cdot \operatorname{sgn}(y(z, d, e, u)) \leq$ $\leq \max \left\{o s\left(p t_{e}(d)\right) ; o s_{u}(u)\right\}$

$$
\begin{gathered}
\forall z \in Z \forall_{d \in D(z)} \forall a \in I(d): n t_{e}(d)=1 \\
\forall u \in U I \cap U(z) \cap U T_{e}(d)
\end{gathered}
$$

$N U(u) \cdot \sum_{u^{\prime} \in U 2 \cap U(z) \cap U T_{e-1}(d) \cap U U(u)} y\left(z, d, e-1, u^{\prime}\right) \geq y(z, d, e, u)$

$$
\begin{gathered}
\forall z \in Z \forall_{d \in D(z)} \forall a \in I(d): n t_{e}(d)=1 \\
\forall u \in U I \cap U(z) \cap U T_{e}(d)
\end{gathered}
$$

$N U(u) \cdot \sum_{u^{\prime} \in U 2 \cap U(z) \cap U T_{e+1}(d) \cap U U(u)} y\left(z, d, e+1, u^{\prime}\right) \geq y(z, d, e, u)$

$\forall_{z \in Z} \forall \forall_{d \in D(z)} \forall_{e \in I(d): n t_{e}(d)=0}$

$\forall u \in U 2: p t_{e}(d) \notin P_{U 2}(u) \quad y(z, d, e, u)=0$

$\forall_{z \in Z} \forall \forall_{d \in D(z)} \forall \mathrm{e} \in I(d): n t_{e}(d)=1$

$\forall u \in U l: p t_{e}(d) \notin P_{U 1}(u) \quad y(z, d, e, u)=0$

$\forall_{z \in Z} \forall d \in D(z) \forall e \in I(d)$

$\forall u \notin U(z) \quad y(z, d, e, u)=0$

$\forall_{z \in Z} \forall d \in D(z) \forall e \in I(d)$

$\forall u \notin U T_{e}(d) \quad y(z, d, e, u)=0$

$\forall_{z \in Z} \forall{ }_{d \in D(z)} \forall \mathrm{e} \in I(d)$

$\forall u \notin T U\left(t t_{e}(d)\right) \quad y(z, d, e, u)=0$

$\forall z \in Z \forall d \notin D(z) \quad x(z, d)=0$

$\forall_{z \in Z} \forall_{b \in B(z)} \forall d \in D(z)$

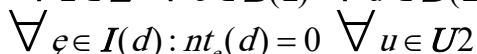

$y(z, d, e, u) \cdot\left(m_{b}(b) \cdot N\left(p t_{e}(d), b\right)+m_{p}\left(p t_{e}(d)\right)\right) \leq F_{Q}(u)$

$\forall_{z \in Z} \forall_{d \in D(z)} \forall_{e \in I(d)}$
$\forall_{u \in U(z) \cap U T_{e}(d)} \forall_{n u(u) \in\{1, \ldots, N U(u)\}}$
$t d_{e}(d, u, n u(u)) \cdot z(z, d, e, u, n u(u)) \leq \tau(z, d, e)$

$\forall{ }_{z \in Z} \forall d \in D(z) \quad t_{p}(z) \leq \tau(z, d, e=1)$ $\forall_{z \in Z} \forall d \in D(z) \forall e \in I(d) \backslash\{1\}$

$\forall u \in U(z) \cap U T_{e}(d) \forall n u(u) \in\{1, \ldots, N U(u)\}$

$\tau(z, d, e-1)+\left[n t_{e-1}(d) \cdot\left(\frac{s\left(t t_{c-1}(d)\right)}{V_{s r}(u)}+t_{d o d}\left(t t_{e-1}(d), u\right)\right)+\right.$ 


$$
\begin{aligned}
& \forall_{z \in Z} \forall d \in D(z) \quad \forall u \in U(z) \cap U T_{e}(d) \\
& \forall n u(u) \in\{1, \ldots, N U(u)\} \quad t_{d}(z) \geq \tau(z, d, e=E(d))+ \\
& +\left[n t_{e=E(d)}(d) \cdot\left(\frac{s\left(t t_{e=E(d)}(d)\right)}{V_{s r}(u)}+t_{d o d}\left(t t_{e=E(d)}(d), u\right)\right)+\right. \\
& \left.+\frac{\left(1-n t_{e=E(d)}(d)\right)}{W\left(u, p t_{e=E(d)}(d)\right)} \cdot \sum_{b \in B(z)} \frac{n(z, b)}{N\left(p t_{e=E(d)}(d), b\right)}\right] . \\
& \cdot z(z, d, e)=E(d), u, n u(u)) \\
& \forall z \in Z \forall d \in D(z) \forall e \in I(d) \\
& \forall u \in U(z) \cap U T_{e}(d) \\
& \sum_{n u(u)=1}^{N U(u)} z(z, d, e, u, n u(u))=y(z, d, e, u)
\end{aligned}
$$

\subsection{Assessment Criterion}

In the model, as the criteria for assessing solutions, the criterion of the total transport costs was included, including the cost of the work of the means of transport and loading equipment, as well as the labor costs of employees servicing them. Formally, this criterion was written as follows:

$$
\begin{gathered}
\sum_{z \in Z} \sum_{d \in D(z)} \sum_{e \in I(d)} \sum_{u \in U T_{e}(d)} y(z, d, e, u) \cdot\left[n t_{e}(d) \cdot s\left(t t_{e}(d)\right) \cdot\right. \\
\cdot k_{t s}(u)+n t_{e}(d) \cdot\left[\frac{s\left(t t_{e}(d)\right)}{V_{s r}(u)}+t_{d o d}\left(t t_{e}(d), u\right)\right] \cdot k_{t t}(u)+ \\
+\frac{\left(1-n t_{e}(d)\right) \cdot k_{j}(u)}{W\left(u, p t_{e}(d)\right)} \cdot \sum_{b \in B(z)} \frac{n(z, b)}{N\left(p t_{e=E(d)}(d), b\right)}+ \\
+k_{d o d}\left(t t_{e}(d), u\right)+\left[n t_{e}(d) \cdot \frac{s\left(t t_{e}(d)\right)}{V_{s r}(u)}+t_{d o d 2}\left(t t_{e}(d), u\right)\right] . \\
\cdot k_{t w}(u)+\left[\frac{\left(1-n t_{e}(d)\right)}{W\left(u, p t_{e}(d)\right)} \cdot \sum_{b \in B(z)} \frac{n(z, b)}{N\left(p t_{e=E(d)}(d), b\right)}+\right. \\
\left.\left.+t_{d o d 2}\left(t t_{e}(d), u\right)\right] \cdot k_{w}(u)+k_{d o d 2}\left(t t_{e}(d), u\right)\right] \longrightarrow \min
\end{gathered}
$$

\section{THE CONCEPT OF THE INTEGRATION OF THE MODEL FOR THE SELECTION OF MULTIMODAL TRANSPORT TECHNOLOGIES WITH THE EPLOS SYSTEM}

In its basic form, the EPLOS system, created as part of the EUREKA initiative, is a database system which integrates, from various sources, information taken into account when making strategic and operational decisions in the area of logistics related to the movement of material goods between economic entities. In the first phase of its implementation, it will cover the Czech Republic, Poland, and the Baltic States. The primary assumed functionality of this tool is to provide information to the TMS class systems and other systems used by individual enterprises (for more detailed characteristics of the EPLOS system, see [30] and [31]). Nevertheless, there is a great potential of the EPLOS tool in terms of their extension with the individual methods of solving decision problems - especially those that are not included in the TMS class systems. One such issue is the selection of multimodal transport technologies for fixed transport tasks.

Assuming that the problem of the selection of multimodal transport technologies is formulated following the model presented in Chapter 2, to solve it, it is justified to use the EPLOS database in the scope of:

- $\quad$ information about the available means of transport (their type, number and supported forms of transport),

- $\quad$ information about the available loading devices (their type, number, capacity, and supported transport forms),

- data on the transport routes for external transport (mileage, length, authorized means of transport, costs of using the infrastructure),

- generating variant solutions for the technological process in transport (searching for transport offers and transshipment options together with the assessment of the availability of the loading equipment and means of transport - the assumed target functionality of the EPLOS system).

The use of the proposed model by using the EPLOS system will, therefore, involve the need to enter additional data regarding:

- cargo characteristics,

- characteristics of transport characters,

- characteristics of the means of transport in terms of guaranteed transport conditions, labor costs, the capacity and the possibility of handling by loading devices,

- characteristics of loading devices in terms of labor costs,

- characteristics of transport routes in internal transport (reloading relations)

- $\quad$ characteristics of the routes of transport in the external transport in terms of the estimated stopping time of the means of transport, the working time of other employees carrying out the movements and their additional labor costs,

- $\quad$ transport tasks.

In the case of extending the functionality of the EPLOS system by planning multimodal transport technologies, it is also possible to include in it a number of catalogs useful in this field, such as the catalog of loads and their characteristics, or the catalog of transport forms. Moreover, it is possible to implement a number of algorithms that estimate the data required to solve the analyzed problem (e.g., characteristics of reloading relations, predicted stoppages of the means of transport, and anticipated times of work of other employees serving them). This approach will minimize the need to manually enter the data that reflects the decision problem in the selection of multimodal load handling technologies.

The described concept of the integration of the model for the selection of multimodal transport technologies with the EPLOS system, taking into account its variant, is schematically presented in Fig. 1. 


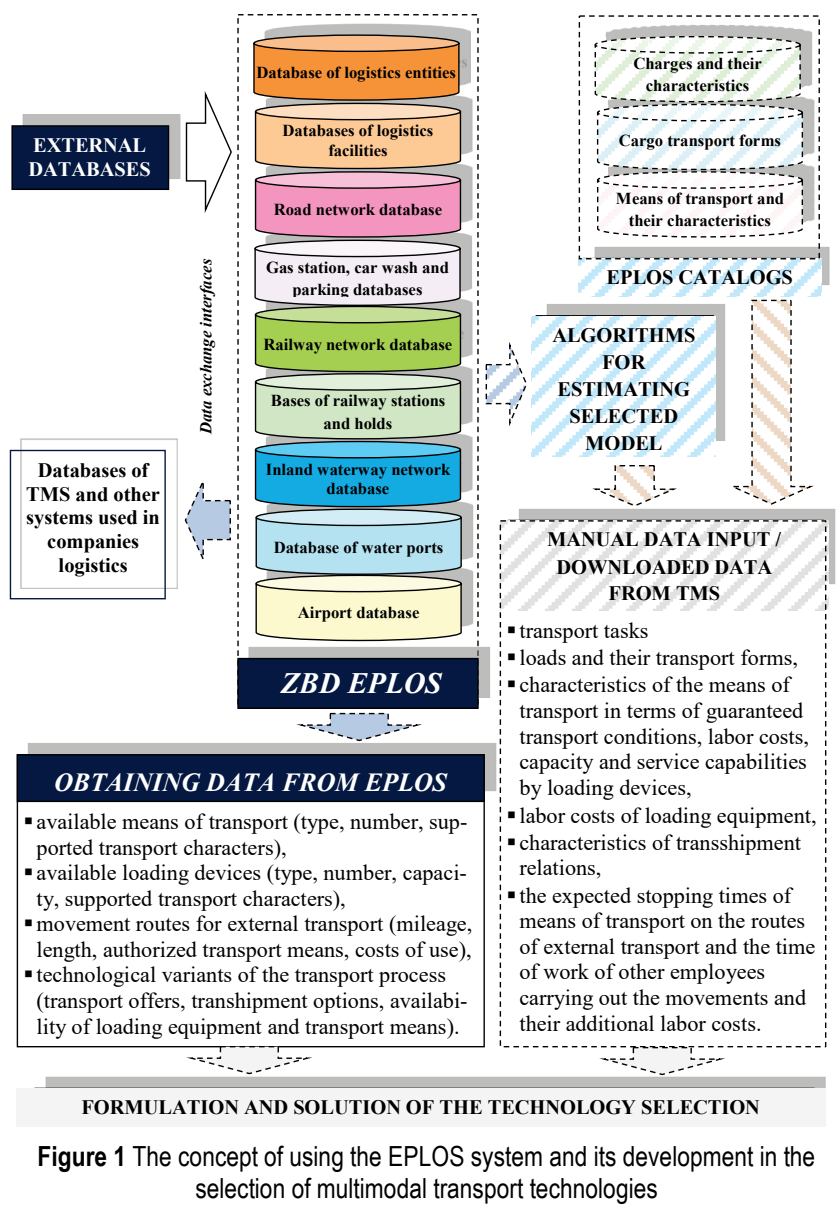

\section{CONCLUSIONS}

The issue of the selection of multimodal transport technologies analyzed in the article can be considered for a specific company that has a specific transport potential, while the implementation of the agreed transport tasks can be carried out with the involvement of both its own logistics potential, as well as the logistics potential of transport and forwarding companies as well as providing reloading services. Assuming that the transport tasks taken into account may relate to the movement of loads with different characteristics and forms of transport in various relations, the problem of the selection of multimodal transport technologies becomes very complex, and its solutions require a number of data that are subject to constant changes in the market economy conditions. This makes it justified to use the EPLOS system and even its extension with additional functionalities (estimation of some model parameters, catalogs).

At the same time, it should be noted that in real conditions, the selection of the best solution in the field of transport technology is often determined by non-cost criteria, such as transport time and load safety. Importantly, these factors are often taken into account simultaneously. This means that it is justified at the next stage to develop the proposed approach by a multi-criteria assessment method of transport technology variants, including, e.g., the point method or the MAJA method [32-34].

\section{Acknowledgments}

This study is the result of work carried out as part of the EPLOS (European Portal of Logistics Services) project under the EUREKA initiative funded by the National Center for Research and Development.

Notice

The paper will be presented at MOTSP 2020 International Conference Management of Technology - Step to Sustainable Production, which will take place from $30^{\text {th }}$ September $-2^{\text {nd }}$ October 2020 in Bol, island Brač (Croatia). The paper will not be published anywhere else.

\section{REFERENCES}

[1] Leleń, P. \& Wasiak, M. (2018). Optimization of Multimodal Transport Technologies Selection for Packed Non-climacteric Vegetables and Fruits. Advanced Solutions of Transport Systems for Growing Mobility Advances in Intelligent Systems and Computing, 631, 203-215.

[2] Leleń, P. \& Wasiak, M. (2019). The model of selecting multimodal technologies for the transport of perishable products. Archives of Transport, 50(2), 17-33. https://doi.org/10.5604/01.3001.0013.557

[3] Leleń, P. \& Wasiak, M. (2017). Wielokryterialny dobór multimodalnych technologii transportu produktów szybko psujących się z uwzględnieniem współczynników podatności transportowej. AUTOBUSY - Technika, Eksploatacja, Systemy Transportowe, 12, 570-574.

[4] Leleń, P. \& Wasiak, M. (2017). Współczynniki podatności transportowej ładunków szybko psujących się. Prace Naukowe Politechniki Warszawskiej. Transport, 117, 161-177.

[5] Wasiak, M. \& Leleń, P. (2018). Uwarunkowania prawne realizacji przewozu ładunków szybko psujących. Prace Naukowe Politechniki Warszawskiej. Transport, 120, 437-446.

[6] Wasiak, M. (2018), Problemy decyzyjne organizacji przewozów transportem drogowym. Oficyna Wydawnicza Politechniki Warszawskiej, Warszawa.

[7] Bieńczak, K. (2011). Zapewnienie bezpieczeństwa konsumentowi żywności w ogniwie transportowym łańcucha chłodniczego. Maintenance and Reliability, 1, 16-26.

[8] Bogdanowicz, S. (2012). Podatność. Teoria i zastosowanie w transporcie. Oficyna Wydawnicza Politechniki Warszawskiej, Warszawa.

[9] Cevoli, C. \& Fabbri, A. (2017). Heat transfer finite element model of fresh fruit salad insulating packages in nonrefrigerated conditions. Biosystems Engineering, 153, 89-98. https://doi.org/10.1016/j.biosystemseng.2016.11.002

[10] Piala, P. \& Dávid, A. (2016). Transport of tropical fruits to central Europe. Nase More, 63(2), 62-65. https://doi.org/10.17818/NM/2016/2.4

[11] Sandhya, S. (2010). Modified atmosphere packaging of fresh produce: Current status and future needs. $L W T-$ Food Science and Technology, 43, 381-392. https://doi.org/10.1016/j.lwt.2009.05.018

[12] Soleimani, B. \& Ahmadi, E. (2014). Measurement and analysis of truck vibration levels as a function of packages locations in truck bed and suspension. Computers \& Electronics in Agriculture, 109, 141-147. https://doi.org/10.1016/j.compag.2014.09.009

[13] Zhu, Q., Guan, J., Huang, M., Lu, R., \& Mendoza, F. (2016). Predicting bruise susceptibility of 'Golden Delicious' apples 
using hyperspectral scattering technique. Postharvest Biology and Technology, 114, 86-94. https://doi.org/10.1016/j.postharvbio.2015.12.007

[14] Zhiguo, L. \& Colin, T. (2014). Quantitative evaluation of mechanical damage to fresh fruits. Trends in Food Science and Technology, 35, 138-150, https://doi.org/10.1016/j.tifs.2013.12.001

[15] Bortolini, M., Faccio, M., Ferrari, E., Gamberi, M., \& Pilati, F. (2016). Fresh food sustainable distribution: Cost, delivery time and carbon footprint three-objective optimization. Journal of Food Engineering, 174, 56-67. https://doi.org/10.1016/j.jfoodeng.2015.11.014

[16] Izdebski, M., et al. (2018). The application of the genetic algorithm to multi-criteria warehouses location problems on the logistics network. Transport, 33(3), 741-750, https://doi.org/10.3846/transport.2018.5165

[17] Jacyna, M. \& Szczepański, E. (2013). Holistic approach to the ecological cargo distribution in urban areas with the use of multimodal transport. WIT Transactions on the Built Environment, 130, 53-65. https://doi.org/10.2495/UT130051

[18] Jacyna-Gołda, I. (2015). Decision-making model for supporting supply chain efficiency evaluation. Archives of Transport, 33(1), 17-31. https://doi.org/10.5604/08669546.1160923

[19] Jacyna-Gołda, I., Izdebski, M., Szczepański, E., \& Gołda, P. (2018). The assessment of supply chain effectiveness. Archives of Transport, 45(1), 43-52. https://doi.org/10.5604/01.3001.0012.0966

[20] Palak, G., Ekşioğlu, S. D., \& Geunes, J. (2018). Heuristic algorithms for inventory replenishment with perishable products and multiple transportation modes. IISE Transactions, 50(4), 345-365. https://doi.org/10.1080/24725854.2017.1405296

[21] Szczepański, E., Jachimowski, R., Izdebski, M., \& JacynaGołda, I., (2019). Warehouse location problem in supply chain designing: a simulation analysis. Archives of Transport, 50(2), 101-110. https://doi.org/10.5604/01.3001.0013.575

[22] Wasiak, M., Jacyna, M., Lewczuk, K., \& Szczepański, E. (2017). The method for evaluation of efficiency of the concept of centrally managed distribution in cities. Transport, 32(4), 348-357. https://doi.org/10.3846/16484142.2017.1345005

[23] Wasiak, M., et al. (2019). The use of a supply chain configuration model to assess the reliability of logistics processes. Maintenance and Reliability, 21(3), 367-374. https://doi.org/10.17531/ein.2019.3.2

[24] van der Vorst, J. G. A. J, Tromp, S. O., \& van der Zee, D. J. (2009). Simulation modelling for food supply chain redesign; integrated decision making on product quality, sustainability and logistics. International Journal of Production Research. 47(23), 6611-6631. https://doi.org/10.1080/00207540802356747

[25] Jacyna, M., Izdebski, M., Szczepański, E., \& Gołda, P. (2018). The task assignment of vehicles for a production company. Symmetry, 10(551), 1-19. https://doi.org/10.3390/sym10110551

[26] Wasiak, M. (2016). Vehicle selection model with respect to Economic Order Quantity. Archives of Transport. 40(4), 7785. https://doi.org/10.5604/08669546.122547

[27] He, P. \& Li, J. (2018). Vehicle routing problem with partly simultaneous pickup and delivery for the cluster of small and medium enterprises. Archives of Transport, 45(1), 35-42. https://doi.org/10.5604/01.3001.0012.0940

[28] Izdebski, M. \& Jacyna, M. (2018). The organization of the municipal waste collection: the decision model. Annual Set The Environment Protection, 20, 919-933.

[29] Song, B. D. \& Ko, Y. D. (2016). A vehicle routing problem of both refrigerated- and general-type vehicles for perishable food products delivery. Journal of Food Engineering, 169, 61-71. https://doi.org/10.1016/j.jfoodeng.2015.08.027
[30] Chen, D., Zhang, Y., Gao, L., \& Thompson, R. G. (2019). Optimizing Multimodal Transportation Routes Considering Container Use. Sustainability, 11(5320), 1-18. https://doi.org/10.3390/su11195320

[31] Min, H., Jayaraman, V., \& Srivastava, R. (1998). Combined location-routing problems: A synthesis and future research directions. European Journal of Operational Research, 108(1), 1-15. https://doi.org/10.1016/S0377-2217(97)00172-0

[32] Jacyna, M., et al. (2019). The Concept of EPOS Database of the Transport Infrastructure. 23rd international scientific conference Transport Means 2019 Sustainability: Research and Solutions Proceedings $23^{\text {rd }}$ International Scientific Conference / Kersys Robertas (ed.), Transport Means, 12501255.

[33] Wasiak, M., et al. (2019). Concept of EPLOS database of logistics facilities. 23 ${ }^{\text {rd }}$ International Scientific Conference Transport Means 2019 Sustainability: Research and Solutions Proceedings $23^{\text {rd }}$ International Scientific Conference / Kersys Robertas (ed.), Transport Means, 1317-1322.

[34] Jacyna, M. (1999). Multicriteria evaluation of traffic flow distribution in a multimodal transport corridor, taking into account logistics base service. Archives of Transport, 11(3-4), 43-66.

[35] Jacyna, M. (2001). Modelowanie wielokryterialne w zastosowaniu do oceny systemów transportowych, Prace Naukowe Politechniki Warszawskiej. Transport, 47, 3-139.

[36] Jacyna, M. \& Wasiak, M. (2015). Multicriteria decision support in designing transport systems. Communications in Computer and Information Science, 531, 11-23. https://doi.org/10.1007/978-3-319-24577-5_2

\section{Authors' contacts: \\ Mariusz Wasiak, Associate Professor, PhD (Eng.) Faculty of Transport, Warsaw University of Technology, Koszykowa 75, room 363, 00-662 Warsaw, Poland mwa@wt.pw.edu.pl \\ Paweł Leleń, PhD (Eng.) \\ Faculty of Transport, Warsaw University of Technology, Koszykowa 75, 00-662 Warsaw, Poland plelen@wt.pw.edu.pl}

Michał Kłodawski, Associate Professor, PhD (Eng.) Faculty of Transport, Warsaw University of Technology, Koszykowa 75, room 366, 00-662 Warsaw, Poland mkloda@wt.pw.edu.pl

Mariusz Izdebski, Associate Professor, PhD (Eng.) Faculty of Transport, Warsaw University of Technology, Koszykowa 75, room 367, 00-662 Warsaw, Poland mizdeb@wt.pw.edu.pl

Ilona Jacyna-Gołda, Associate Professor, PhD (Eng.) Faculty of Production Engineering, Warsaw University of Technology, Narbutta 85, room 120, 02-524 Warsaw, Poland ilona.golda@pw.edu.pl 